\title{
The Use of Artificial Neural Networks (ANN) in Food Process Engineering
}

\author{
Raquel P. F. Guiné \\ CI\&DETS/ESAV, Polytechnic Institute of Viseu, Department of Food Industry, Viseu, Portugal \\ Email: raquelguine@esav.ipv.pt
}

\begin{abstract}
Artificial neural networks (ANN) aim to solve problems of artificial intelligence, by building a system with links that simulate the human brain. This approach includes the learning process by trial and error. The ANN is a system of neurons connected by synaptic connections and divided into incoming neurons, which receive stimulus from the external environment, internal or hidden neurons and output neurons, that communicate with the outside of the system. The ANNs present many advantages, such as good adaptability characteristics, possibility of generalization and high noise tolerance, among others. Neural networks have been successfully used in various areas, for example, business, finance, medicine, and industry, mainly in problems of classification, prediction, pattern recognition and control. In the food industry, food processing, food engineering, food properties or quality control, statistical tools are frequently present, and ANNs can process more efficiently data comprising multiple input and output variables. The objective of this review was to highlight the application of ANN to food processing, and evaluate its range of use and adaptability to different food systems. For that a systematic review was undertaken from the scientific literature and the selection of the information was based on inclusion criteria defined. The results indicated that ANN is widely used for modelling and prediction in food systems, showing good accuracy and applicability to a wide range of situations and processes in food engineering.
\end{abstract}

Index Terms-algorithm, ANN, food processing, food modelling, prediction

\section{INTRODUCTION}

Artificial neural networks (ANNs) constitute a group of nonlinear regression and discrimination statistical methods with predictive capacity and which have been widely studied. ANNs correspond to computational systems that aim to imitate some properties of biological neurons. Methods based on ANNs imitate the natural neural system via computer programs being fairly popular due to several advantages such as, for example: nonlinearity, adaptation, generalization, model independence, easy to use and high accuracy [1], [2].

The first artificial model of a biological neuron was obtained in 1943 by the pioneering work of Warren McCulloch (psychiatrist and neuroanatomist) and Walter Pitts (mathematician). Their work focused essentially on the creation of an artificial model of a neuron and presented its computational capabilities and not so much

Manuscript received November 20, 2018; revised March 2, 2019. in developing learning technologies. Part of the discussion in ANNs involves learning methods in order to be able to perform a certain function [3].

An artificial neural network corresponds to a technique of numerical estimation that allows simulate the learning and memorizing process. It is a potent tool that learns based on the experimental input variables and finds the governing rules between the corresponding factors [4].

In order to characterize ANNs, three concepts are necessary to define: neuron, which is the basic computational unit in the network in question; architecture, the topological structure of how the neurons are connected; learning, the process that adapts the network in order to compute a desired function or perform an assignment. An ANN structure comprises an input layer, hidden layer(s) and an output layer of neurons. ANN connection weights are coefficients used to determine the relative importance of the different inputs, and a number of equations are available to assess the relative importance based on the magnitude of the weights [5], [6].

ANN uses known data, i.e. previously solved examples, recognizes complex patterns between inputs and outputs so that it can later apply that knowledge on new unknown data. This is possible through the learning of the hidden relationships between inputs and outputs with subsequent use of the ANN in the prediction of output from the given input of new data. After adequate training, the neural networks attempt to predict the outcomes, having a higher accuracy than conventional classification or regression analysis. Due to the ability to detect complex nonlinear relationships between predictors and outcomes, ANN has been successfully used in several areas of knowledge, from computation to medicine [7]. Therefore, ANN has been widely and successfully used in various fields to predict the influence of some targeted variables (inputs) on the investigated outputs [8]. In recent years, there is greater interest in using neural networks as problem solving algorithms which can perform mapping, regression, modelling, clustering, classification and multivariate data analysis. ANNs are highly flexible, which makes then ideal to solve highly non-linear problems and deal with any kind of data. Owing to its adaptability, ANN methods have been successfully employed by numerous researchers to model and predict many different processes in the food industry, food processing, food engineering, food properties or quality control [9]. 
The objective of this review was to highlight the application of ANN to food processing, and evaluate its range of use and adaptability to different food systems.

\section{METHODS}

A systematic review was undertaken in scientific databases like Science Direct, BOn or PubMed. For the review a number of keywords were selected, to target the topics related to the use of ANN in food process engineering. The combination of words used was ANN + Neural Network + Food.

The information was selected following the inclusion criteria defined: diversity of approaches and applications, variability in processing techniques, range of food products and publication date.

The information was organized according to basic principles of ANN modelling, followed by the specific applications, according to the processes addressed.

\section{ANN PRINCIPLES}

The aim of neuronal networks is to create a computational model of the human brain, in order to achieve a machine able to parallel the capacity of the human thinking - machine learning. For this, it is intended to mimic the functioning of the human brain and create a digital copy [10], [11].

The human brain is responsible for the emotions, thoughts, perceptions and cognition, as well as for the execution of sensorimotor and autonomous functions. The human brain weighs approximately $1.5 \mathrm{~kg}$ and uses $20 \%$ to $25 \%$ of the energy of the human body. The brain has about $10^{11}$ neurons, $10^{4}$ connections per neuron. In a day $10^{5}$ neurons die and zero neurons are born. The rhythm of creation of new connections is very slow, but the commuting time is $10^{-3}$ seconds. The available memory has $10^{15}$ connections [12], [13].

The neuron can be considered the basic structural unit of the brain and nervous system. A biological neuron has three types of components with particular interest for artificial intelligence: dendrite, cell body and axon (Fig. 1) [13], [14]. The dendrite receives activation signals from other neurons, which are electrical impulses transmitted by electrochemical processes through synapses. The cell body adds the input signals and if the sum achieves a certain value the neuron sends a signal, which will propagate through the axon into other neurons [13].

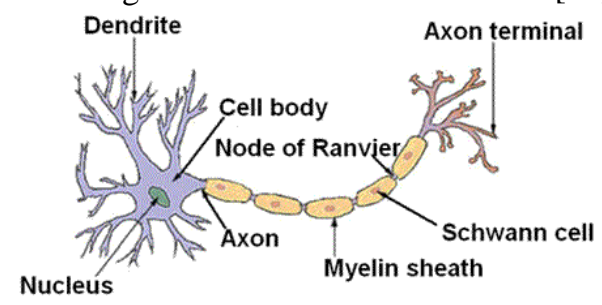

Figure 1. Structure of a biological neuron

Neuronal networks are computational programs that implement detection of sophisticated patterns and learning algorithms, allowing to build predictive models from wide data basis [15]. Their name derives from the parallelism established with the architecture of the human brain. The neuron network and its synapses constitute the model that can be implemented artificially through special hardware and software programs. An artificial neuronal network is a computational model characterized by a number of simple elements, similar to biological neurons, and a network of directed connections, with associated weights between the neurons [16]. The signal from each input is multiplied by a weighting factor of the input and added to other signals multiplied by the corresponding weighting factors [16]. The weights are positive or negative real numbers.

The operation of an artificial neuron (Fig. 2) comprises the following steps [3]:

- The signals are presented as inputs $\left(X_{1}\right.$ to $\left.X_{m}\right)$;

- Each signal is multiplied by a weight $\left(\mathrm{W}_{\mathrm{k}}\right)$, which indicates its influence in the output unit;

- All signals are weighted and added producing a level of activity $\left(\mathrm{U}_{\mathrm{k}}\right)$;

- The activation function $f\left(\mathrm{U}_{\mathrm{k}}\right)$ limits the output and introduces non-linearity in the model;

- The bias $\left(b_{k}\right)$ aims at increasing or decreasing the influence of the value of the inputs;

- The bias is like an input of constant value equal to 1 , multiplied by a weight equal to $b_{k}$.

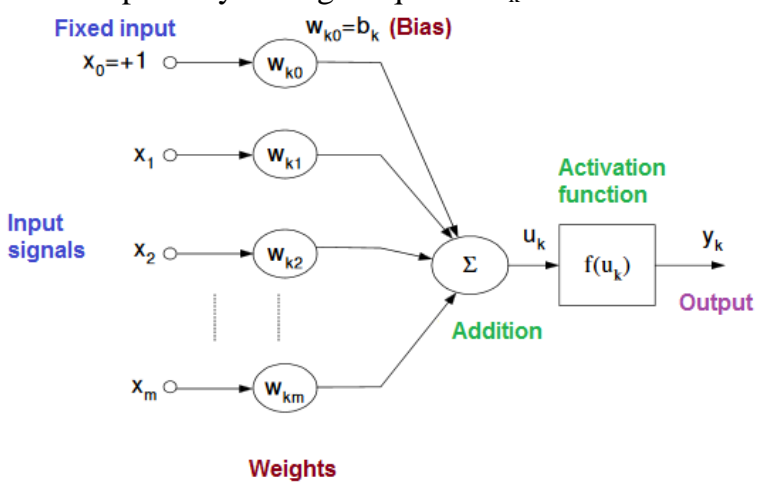

Figure 2. Model of an artificial neuron.

The activation function can be in various forms, generally non-linear. The four more commonly used activation functions are Binary (Step), Linear (Slope), Sigmoid (Logistic) and Tanh (Hyperbolic tangent).

The architecture of neuronal networks is typically organized in layers with units that can be connected to the units in the following layer (Fig. 3).

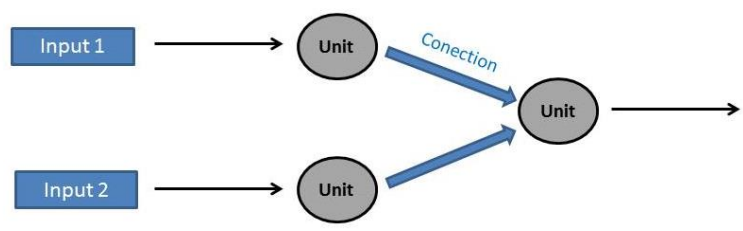

Figure 3. Basic architecture of an ANN.

Fig. 4 shows a typical network with multiple layers. The input layer corresponds to the independent variables. The hidden layers can be numerous, and normally the number of hidden layers increases with the increasing number of input units and the complexity of the problem. Too many hidden units can lead to over-training and too 
few can result in low precision models. The output layer can have one or mode output units, and corresponds to the dependent variables [17].

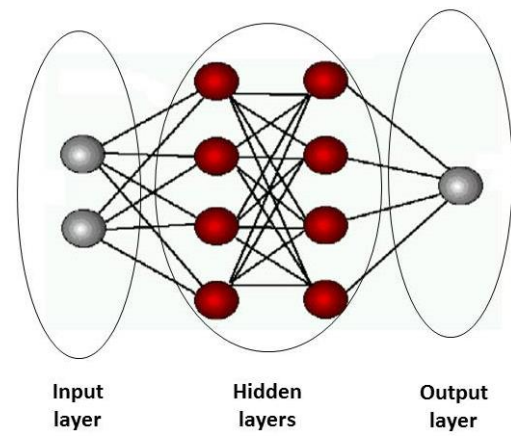

Figure 4. Architecture of a multilayer ANN.

Fig. 5 shows the structure of a multi-layer feed forward network developed with the software MATLAB. The ANN has an input layer, an output layer and a hidden layer, with variable number of neurons. This net aims to compute in an intelligent way the complex interconnections of neurons, which are the constitutive units of ANN [18]. Just like in the case of biological neurons, artificial neurons receive one or more inputs and sum them to generate an output. This is done by means of an activation function. The network receives a number of inputs and is told about the targeted outputs.

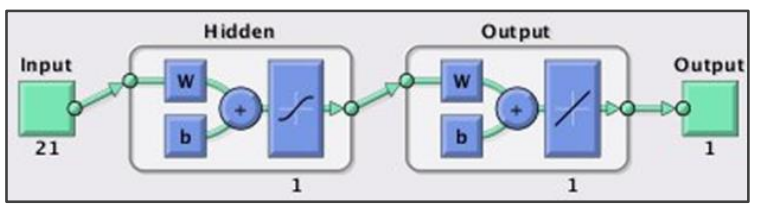

Figure 5. Example of ANN structure

There are three stages in the processing by the network, which include: train, validation and test. Typically, about $70 \%$ of the experimental data is used for training, $15 \%$ for validation, and the rest of the data for testing, all selected randomly from the set of experimental data available [19].

Initially, random initial weights are attributed to each of the inputs to start the first step. Then, a LevenbergMarquardt backpropagation training algorithm will induce changes in the weights to adapt them to the best solution. Hence, the training will come to an end when satisfactory results are achieved. At this stage the results move in the forward direction from the hidden layer towards the output layer, which has a linear activation function. The validation is carried out, by adjusting the combination through a number of iterations, so as to generate reasonable parameters for the learning algorithm. Finally, the network is tested in order to assess its prediction accuracy, by calculating the mean squared error (MSE) [4].

\section{APPLICATION OF ANN TO FOOD PROCESSES}

\section{A. Drying}

The application of ANN to a large range of fields was described in the scientific literature for modelling and prediction in energy-engineering systems. Tripathy and Kumar [20] used an ANN approach to predict the product temperature during solar drying of foodstuffs, using data from the solar drying of potato to develop the ANN model. They concluded that optimal neural network was achieved with 4 neurons, logsig transfer function and trainrp (back propagation algorithm), based on lowest error calculations.

Also Azadbakht and Icier [21] applied ANN to model the energy and exergy parameters in fluidized bed drying of potato samples. Besides, the ANN model allowed simulating the thermodynamics of the drying process.

Nazghelichi et al. [22] optimized an ANN configuration for the fluidized bed drying of carrots. A multi-layer feed forward ANN was used to correlate the outputs (energy and exergy) to the four exogenous inputs (drying time, drying air temperature, carrot cubes size and bed depth). The configuration showed the lowest MSE for the following conditions: 28 neurons in the hidden layer; momentum coefficient equal to 0.66 ; step size of 0.35 ; number of training epochs 2877; and 3 training times. The energy and exergy were predicted with values of the determination coefficient greater than 0.97 .

Momenzadeh et al. [23] applied ANN modelling to the drying of shelled corn in a fluidized bed assisted with microwave (MW) heating, in the temperature range from 30 to $60{ }^{\circ} \mathrm{C}$ and $\mathrm{MW}$ power from 180 to $900 \mathrm{~W}$. The ANN configuration possessed 170 neurons and the results indicated that a network with the Tansig (hyperbolic tangent sigmoid) transfer function and trainrp (resilient back propagation) algorithm allowed the most accurate predictions.

Khazaei et al. [24] used applied machine vision and ANN for modelling and control of the grape drying process with real-time prediction of moisture content. The most suitable ANN was achieved with three layers: input layer with 4 nodes (units), one hidden layer with 5 nodes and one output layer with 1 node.

Aktaş et al. [25] evaluated the performance and modelled the drying of bay leaves in a closed-loop heat pump dryer, by means of ANN. The back-propagation learning algorithm with Levenberg-Marquardt and Fermi transfer function were used in the network, which demonstrated a high coefficient of determination (0.996).

Karimi et al. [26] also used ANN to select the optimum drying conditions for the convective drying of mugwort leaves. The input variables were air temperature, air velocity and drying time, and the output variables were the moisture content, drying rate, and energy and exergy efficiencies.

Çakmak and Yıldız [27] developed a feed forward ANN predictive model for the drying kinetics of seedy grapes, which showed good performance in estimating the drying rates. The configuration had 10 neurons and hyperbolic tangent sigmoid activation function with Levenberg-Marquardt optimization technique.

Movagharnejad and Nikzad [28] studied the experimental drying of tomatoes in a tray drier, by varying the process parameters heating power and air 
flow rate, and the data were used to model the process by ANN. Their work clearly indicated that the ANN model described the drying behaviour more accurately when compared to empirical correlations. Furthermore, they concluded that the major advantage of ANN models over empirical equations, besides accuracy, was their generalizing applicability. ANN models can describe a range of experiments while the empirical equations are only valid to a specific experiment.

Hernández [29] optimized the operating conditions for heat and mass transfer during drying of food products by ANN, and concluded that it was suitable to determine the optimal parameters during the drying of mango and cassava.

\section{B. Extraction and Separation Techniques}

The kinetics of extraction of essential oils from tarragon using ultrasound pre-treatment was modelled with ANN by Bahmani et al. [30]. They generated a three-layer perceptron network with an error backpropagation algorithm to predict the extraction. The input variables considered were ultrasound power, sonication time, extraction time and their interactions, and the output addressed was the extraction yield.

Ameer et al. [31] used ANN to optimize microwaveassisted extraction of natural sweeteners from stevia leaves. They concluded that ANN can reliably model the process as compared to RSM, showing higher predictive and estimation capabilities.

Also Simić et al. [32] optimized the microwaveassisted extraction of total polyphenols from chokeberries by means of ANN, which had 1 input, 1 hidden and 1 output layers. The input layer had 3 neurons (ethanol concentration, microwave power, extraction time). The output layer had one neuron (yield of polyphenolic compounds). The use of the ANN with the LevenbergMarquardt (LM) included training (70\% of the data), test ( $15 \%$ of the data) and validation (15\% of the data).

The supercritical extraction of bioactive compounds from coriander seeds was studied by Zeković et al. [8], who performed the process optimization by ANN. The developed model had 3 input variables (pressure, temperature and $\mathrm{CO}_{2}$ flow rate) and one output (initial slope obtained from the kinetic model, which was chosen as a response for the optimization).

\section{Extrusion}

Cubeddu et al. [33] used ANN chains for configuration and control of food extrusion. They aimed to optimize the process variables (inputs: screw speed and water content) having in mind some desired product characteristics (outputs).

Shankar and Bandyopadhyay [34] used a backpropagation ANN model to predict the properties of extrudates of fish muscle/rice flour blend produced by extrusion cooking.

\section{Fermentation}

León-Roque et al. [35] applied ANN to develop a quantitative model to predict fermentation in cocoa beans based on colour measurements. The colour coordinates of the beans surface and extracts were used as predictors in the ANN model. In this way, a simple image based quantitative procedure, using colour measurement and ANN, was developed as a low-cost and in situ procedure for easy prediction of the fermentation index of cocoa beans, through apps developed for mobile devices.

\section{E. High Pressure Processing}

High pressure processing (HPP) is a technology used in the food industry, which has proven very adequate and offers many important advantages when compared to thermal processing. However, the results obtained after HPP treatment depend both on the pressure and temperature used during the treatment. In this way, Torrecilla et al. [36] modelled the thermal behaviour of foods during HPP by ANN, in order to predict process parameters involved in thermal/pressure food processing. The ANN input variables included: applied pressure, rate of pressure increase, set point temperature, temperature of the HPP container and ambient temperature. The ANN used was a perceptron model also known as backpropagation perceptron. The configuration included one input, one hidden and one output layers.

\section{F. Powder Technology}

Benković et al. [37] applied ANN to model the changes in physical and chemical properties of cocoa powder mixtures during agglomeration. The cocoa powder mixtures contained cocoa powders with different fat concentrations and several sweeteners. For the ANN model the input variables considered were agglomeration conditions and mixture composition, while the output variables were the physical and chemical properties of the mixtures. The performance of the model was fair, with high values of the determination coefficient (training: $\mathrm{R}^{2}$ $=0.969$; test: $\mathrm{R}^{2}=0.945$; validation: $\left.\mathrm{R}^{2}=0.934\right)$.

\section{APPLICATION OF ANN IN FOOD QUALITY AND PROPERTIES}

\section{A. Chemical Composition and Nutrients}

Guiné et al. [38] used ANN modelling to predict antioxidant activity and total phenolic compounds content in bananas which were submitted to different drying processes. Their results allowed concluding that the evaluated properties were greatly affected by drying, but hot air drying induced more changes when compared to lyophilization.

Also Musa et al. [39] predicted with accuracy the antioxidant activity of several food products (cinnamon, clove, mung bean, red bean, red rice, brown rice, black rice and tea extract). Their work allowed concluding that the application of ANN was in accordance with the experimental spectrophotometric procedure, allowing to save time and reagents.

Cimpoiu et al. [40] also used ANN to predict the antioxidant activity in teas, in order to characterize and classify them. Hence, two types of ANN based applications were formulated: one for predicting the antioxidant activity and the second to classify the teas. 
Santos et al. [41] applied ANN to detect 13 bioactive phenolic compounds in guava, and it showed good discriminating ability for ripe and unripe fruits.

The moisture content of food products during drying was predicted by Topuz [42] by means of ANN. In his work, ANN allowed estimation of the drying characteristics of agricultural products like hazelnut, bean and chickpea. The ANN was trained through the back propagation algorithm. The results showed fairly good agreement between predicted results and the experimental data. Furthermore, the statistical parameters used to evaluate the model accuracy (mean relative error and mean absolute error), were acceptable.

Also Mohebbi et al. [43] conducted a similar study about predicting the moisture content in bananas submitted to pre-treatments of osmosis and ultrasound before drying in the temperature range from 60 to $80^{\circ} \mathrm{C}$, using ANN. The optimum configuration contained 7 neurons in the first hidden layer and 10 in the second, and it was able to predict moisture content of the dried banana with $\mathrm{R}=0.94$.

Lertworasirikul and Tipsuwan [44] estimated by ANN the moisture content and water activity of semi-finished cassava crackers obtained from drying in the temperature range from 50 to $80^{\circ} \mathrm{C}$. The network comprised 9 hidden nodes and used a logarithmic sigmoid transfer function in the first layer. The regression coefficient was 0.991.

Eim et al. [45] used ANN for the optimization of the added amount of dietary fibre from carrot into a dry fermented sausage, having in mind the product quality by limiting the values of some physical-chemical and textural properties.

\section{B. Texture and Rheology}

Considering that firmness is one of the most important properties of fresh fruits, and is highly connected with shelf-life, Torkashvand et al. [2] used ANN models to develop predictive methods for fruit firmness of kiwis. Their results seemed to indicate that the ANN model showed better potential in determining the relationship between firmness and nutrients concentration, when compared to the predictive capacity of multiple linear regression.

Vásquez et al. [46] applied ANN to predict hardness of cheese during the maturation process, and their work allowed verifying that it had slightly better performance when compared to partial least squares regression models.

The viscoelastic behaviour of pomegranate was investigated by Saeidirad et al. [47] and modelled through ANN. The neural estimation model was built to predict pomegranate stress relaxations, and was seen as an alternative to the Maxwell model.

\section{Colour}

Nadian et al. [48] used ANN models to evaluate the changes in colour of apple slices submitted to drying with hot air circulating at $1-2 \mathrm{~m} / \mathrm{s}$, in the temperature range from 50 to $70^{\circ} \mathrm{C}$. Their objective was to use a computer vision system complemented with ANN as a non-invasive, low cost, and easy method for fast and in-line assessing and controlling the colour and moisture changes in food during drying. They concluded that the tested approach was successful to track and control apple slices' colour changes in real time, thus allowing to obtain better quality products.

\section{Thermal Conductivity}

The thermal conductivity of food products is necessary in process calculations in which heat transfer is involved. This thermal property of foods is influenced by the product composition, structure, and processing conditions. The thermal conductivities of foods are very complex when considered below and above freezing point. Rahman et al. [49] used ANN to develop thermal conductivity prediction models for various fruits and vegetables.

\section{E. Classification and Quality Control}

Lai et al. [4] modelled by ANN the electrostatic separation for roll-type separator initially conceived for assuring security ion the food industry, like for example, to remove hairs or waste straws during packaging process.

In the work by Wang et al. [50] ANN was used for food quality evaluations. The supply chain quality evaluations establish the firm's quality management process, and when they fail the safety incidents are more frequent. They proposed an improved food traceability system that allows forward and diverse tracing complemented with real-time evaluation of food quality along the supply chain making it possible for consumers to assess that information, and therefore trust the companies providing the food products. Their results indicated that the improved traceability system performed well in food quality assurance and evaluation. Furthermore, implications of the proposed approach were also discussed.

ANN classifiers have been successfully implemented for several tasks related to quality inspection and classification for various food products. Dębska and Guzowska-Świder [9] described the use of ANN for the classification of beer samples according to their quality grade.

Rocha et al. [51] applied a feed-forward ANN configuration to assess and quantify the fraudulent adulteration of milk by addition of whey.

The authentication and origin of extra-virgin olive oil cultivars constitutes a challenge and the development of efficient and accurate methods to perform it is difficult due to a wide range of variables that influence the olive oil properties (e.g., multiplicity of varieties, pedo-climatic aspects, as well as production and storage conditions). In their study Binetti et al. [52] applied ANN on several analytical datasets to achieve that goal, with accuracies over $99 \%$ in some cases.

Oladunjoye et al. [53] used ANN for the prediction of bacterial growth on fresh-cut foods (tomatoes and carrots) treated with bactericide agents (bacteriophage and sucrose monolaurate). The prediction with logistic activation function showed the highest positive correlation between predicted and observed values with $\mathrm{R}^{2} \sim 0.9$, hence offering an adequate prediction capacity for phage biocontrol of pathogens in fresh foods. 
Peaches under cold storage can develop chill damage, leading to deterioration in texture and loss of juice. Hence, to maximize fruit quality, Pan et al. [54] established a hyperspectral imaging system to detect cold injury, and developed an ANN model. Their work confirmed the viability of hyperspectral reflectance imaging for identifying cold injury, since the ANN prediction models for quality characteristics presented high correlation coefficients, varying from 0.698 to 0.903 .

\section{CONCLUSION}

The ANNs have proven to be particularly adequate to solve many different problems in the food processing, food engineering and food properties domains. Therefore its usage has become quite frequent and in general the results obtained consubstantiate the fact of being a powerful tool, very practical and low resource consuming.

\section{ACKNOWLEDGMENT}

Thanks to financial support from national funds through FCT - Fundação para a Ciência e Tecnologia, I.P., under the project UID/Multi/04016/2016. Thanks to the Polytechnic Institute of Viseu and CI\&DETS for their support.

\section{REFERENCES}

[1] Q. Song, Y. J. Zheng, Y. Xue, W. G. Sheng, and M. R. Zhao, “An evolutionary deep neural network for predicting morbidity of gastrointestinal infections by food contamination," Neurocomputing, vol. 226, no. Supplement C, pp. 16-22, Feb. 2017.

[2] A. M. Torkashvand, A. Ahmadi, and N. L. Nikravesh, "Prediction of kiwifruit firmness using fruit mineral nutrient concentration by artificial neural network (ANN) and multiple linear regressions (MLR)," Journal of Integrative Agriculture, vol. 16, no. 7, pp. 1634-1644, Jul. 2017.

[3] I. P. Gualda, Aplicação de Redes Neurais Artificiais na Ciência e Tecnologia de Alimentos: Estudo de Casos, Brazil: University of Londrina, 2008.

[4] K. C. Lai, S. K. Lim, P. C. Teh, and K. H. Yeap, "Modeling electrostatic separation process using Artificial Neural Network (ANN)," Procedia Computer Science, vol. 91, no. Supplement C, pp. 372-381, Jan. 2016.

[5] H. Zhang and P. V. Zimba, "Analyzing the effects of estuarine freshwater fluxes on fish abundance using artificial neural network ensembles," Ecological Modelling, vol. 359, no. Supplement C, pp. 103-116, Sep. 2017.

[6] A. Giwa, S. Daer, I. Ahmed, P. R. Marpu, and S. W. Hasan, "Experimental investigation and artificial neural networks ANNs modeling of electrically-enhanced membrane bioreactor for wastewater treatment," Journal of Water Process Engineering, vol. 11, no. Supplement C, pp. 88-97, Jun. 2016.

[7] E. Disse, et al., "An artificial neural network to predict resting energy expenditure in obesity," Clinical Nutrition, Sep. 2017.

[8] Z. Zeković, O. Bera, S. Đurović, and B. Pavlić, "Supercritical fluid extraction of coriander seeds: Kinetics modelling and ANN optimization," The Journal of Supercritical Fluids, vol. 125, no. Supplement C, pp. 88-95, Jul. 2017.

[9] B. Dębska and B. Guzowska-Świder, "Application of artificial neural network in food classification," Analytica Chimica Acta, vol. 705, no. 1, pp. 283-291, Oct. 2011.

[10] P. Joshi, Artificial Intelligence with Python, Birmingham; Mumbai: Packt Publishing, 2017.

[11] K. Warwick, Artificial Intelligence: The Basics, 1 edition, London: Routledge, 2012.

[12] R. Milo and R. Phylips, Cell Biology by the Numbers, USA: Garland Science, 2015.
[13] C. Wang and W. Slikker, Neural Cell Biology, USA: CRC Press, Taylor \& Francis Group, 2017.

[14] K. S. Matlin, J. Maienschein, and M. D. Laubichler, Visions of Cell Biology, Chicago, USA: University Chicago Press, 2017.

[15] G. Gurkaynak, I. Yilmaz, and G. Haksever, "Stifling artificial intelligence: Human perils," Computer Law \& Security Review, vol. 32, no. 5, pp. 749-758, Oct. 2016.

[16] A. Amirov, O. Gerget, D. Devjatyh, and A. Gazaliev, "Medical data processing system based on neural network and genetic algorithm," Procedia - Social and Behavioral Sciences, vol. 131, no. Supplement C, pp. 149-155, May 2014.

[17] K. Gurney, An Introduction to Neural Networks, USA: CRC Press, Taylor \& Francis Group, 1997.

[18] J. Waters and T. Wittman, Quantitative Imaging in Cell Biology, 1st Ed., vol. 123. USA: Academic Press, 2014.

[19] H. Esfandian, A. Samadi-Maybodi, M. Parvini, and B. Khoshandam, "Development of a novel method for the removal of diazinon pesticide from aqueous solution and modeling by artificial neural networks (ANN)," J. Ind. Eng. Chem., vol. 35, pp. 295-308, 2016.

[20] P. P. Tripathy and S. Kumar, "Neural network approach for food temperature prediction during solar drying," International Journal of Thermal Sciences, vol. 48, no. 7, pp. 1452-1459, Jul. 2009.

[21] M. Azadbakht, H. Aghili, A. Ziaratban, and M. V. Torshizi, "Application of artificial neural network method to exergy and energy analyses of fluidized bed dryer for potato cubes," Energy, vol. 120, no. Supplement C, pp. 947-958, Feb. 2017.

[22] T. Nazghelichi, M. Aghbashlo, and M. H. Kianmehr, "Optimization of an artificial neural network topology using coupled response surface methodology and genetic algorithm for fluidized bed drying," Computers and Electronics in Agriculture, vol. 75, no. 1, pp. 84-91, Jan. 2011.

[23] L. Momenzadeh, A. Zomorodian, and D. Mowla, "Experimental and theoretical investigation of shelled corn drying in a microwave-assisted fluidized bed dryer using Artificial Neural Network," Food and Bioproducts Processing, vol. 89, no. 1, pp. 15-21, Jan. 2011.

[24] N. B. Khazaei, T. Tavakoli, H. Ghassemian, M. H. Khoshtaghaza, and A. Banakar, "Applied machine vision and artificial neural network for modeling and controlling of the grape drying process," Computers and Electronics in Agriculture, vol. 98, no. Supplement C, pp. 205-213, Oct. 2013.

[25] M. Aktaş, İ. Ceylan, and S. Yilmaz, "Determination of drying characteristics of apples in a heat pump and solar dryer," Desalination, vol. 239, no. 1, pp. 266-275, abril 2009.

[26] F. Karimi, S. Rafiee, A. Taheri-Garavand, and M. Karimi, "Optimization of an air drying process for Artemisia absinthium leaves using response surface and artificial neural network models," Journal of the Taiwan Institute of Chemical Engineers, vol. 43, no. 1, pp. 29-39, Jan. 2012.

[27] G. Çakmak and C. Yıldız, "The drying kinetics of seeded grape in solar dryer with PCM-based solar integrated collector," Food and Bioproducts Processing, vol. 89, no. 2, pp. 103-108, 2011.

[28] K. Movagharnejad and M. Nikzad, "Modeling of tomato drying using artificial neural network," Computers and Electronics in Agriculture, vol. 59, no. 1, pp. 78-85, Nov. 2007.

[29] J. A. Hernández, "Optimum operating conditions for heat and mass transfer in foodstuffs drying by means of neural network inverse," Food Control, vol. 20, no. 4, pp. 435-438, Apr. 2009.

[30] L. Bahmani, M. Aboonajmi, A. Arabhosseini, and H. Mirsaeedghazi, "ANN modeling of extraction kinetics of essential oil from tarragon using ultrasound pre-treatment," Engineering in Agriculture, Environment and Food, Oct. 2017.

[31] K. Ameer, S. W. Bae, Y. Jo, H. G. Lee, A. Ameer, and J. H. Kwon, "Optimization of microwave-assisted extraction of total extract, stevioside and rebaudioside-A from Stevia rebaudiana (Bertoni) leaves, using response surface methodology (RSM) and artificial neural network (ANN) modelling," Food Chemistry, vol. 229, no. Supplement C, pp. 198-207, Aug. 2017.

[32] V. M. Simić, et al., "Optimization of microwave-assisted extraction of total polyphenolic compounds from chokeberries by response surface methodology and artificial neural network," Separation and Purification Technology, vol. 160, pp. 89-97, Feb. 2016.

[33] A. Cubeddu, C. Rauh, and A. Delgado, "Hybrid artificial neural network for prediction and control of process variables in food 
extrusion," Innovative Food Science \& Emerging Technologies, vol. 21, no. Supplement C, pp. 142-150, Jan. 2014.

[34] T. J. Shankar and S. Bandyopadhyay, "Prediction of extrudate properties using artificial neural networks," Food and Bioproducts Processing, vol. 85, no. 1, pp. 29-33, Mar. 2007.

[35] N. León-Roque, M. Abderrahim, L. Nuñez-Alejos, S. M. Arribas, and L. Condezo-Hoyos, "Prediction of fermentation index of cocoa beans (Theobroma cacao L.) based on color measurement and artificial neural networks," Talanta, vol. 161, no. Supplement C, pp. 31-39, Dec. 2016.

[36] J. S. Torrecilla, L. Otero, and P. D. Sanz, "A neural network approach for thermal/pressure food processing," Journal of Food Engineering, vol. 62, no. 1, pp. 89-95, Mar. 2004.

[37] M. Benković, et al., "Artificial neural network modelling of changes in physical and chemical properties of cocoa powder mixtures during agglomeration," LWT - Food Science and Technology, vol. 64, no. 1, pp. 140-148, Nov. 2015.

[38] R. P. F. Guiné, M. J. Barroca, F. J. Gonçalves, M. Alves, S. Oliveira, and M. Mendes, "Artificial neural network modelling of the antioxidant activity and phenolic compounds of bananas submitted to different drying treatments," Food Chemistry, vol. 168, pp. 454-459, Fevereiro 2015.

[39] K. H. Musa, A. Abdullah, and A. Al-Haiqi, "Determination of DPPH free radical scavenging activity: Application of artificial neural networks," Food Chemistry, vol. 194, no. Supplement C, pp. 705-711, Mar. 2016.

[40] C. Cimpoiu, V. M. Cristea, A. Hosu, M. Sandru, and L. Seserman, "Antioxidant activity prediction and classification of some teas using artificial neural networks," Food Chemistry, vol. 127, no. 3, pp. 1323-1328, Aug. 2011.

[41] W. N. L. dos Santos, M. C. da Silva Sauthier, A. M. P. dos Santos, D. de A. Santana, R. S. A. Azevedo, and J. da C. Caldas, "Simultaneous determination of 13 phenolic bioactive compounds in guava (Psidium guajava L.) by HPLC-PAD with evaluation using PCA and Neural Network Analysis (NNA)," Microchemical Journal, vol. 133, pp. 583-592, Jul. 2017.

[42] A. Topuz, "Predicting moisture content of agricultural products using artificial neural networks," Advances in Engineering Software, vol. 41, no. 3, pp. 464-470, Mar. 2010

[43] M. Mohebbi, F. Shahidi, M. Fathi, A. Ehtiati, and M. Noshad, "Prediction of moisture content in pre-osmosed and ultrasounded dried banana using genetic algorithm and neural network," Food and Bioproducts Processing, vol. 89, no. 4, pp. 362-366, Oct. 2011.

[44] S. Lertworasirikul and Y. Tipsuwan, "Moisture content and water activity prediction of semi-finished cassava crackers from drying process with artificial neural network," Journal of Food Engineering, vol. 84, no. 1, pp. 65-74, Jan. 2008.

[45] V. S. Eim, S. Simal, C. Rosselló, A. Femenia, and J. Bon, "Optimisation of the addition of carrot dietary fibre to a dry fermented sausage (sobrassada) using artificial neural networks," Meat Science, vol. 94, no. 3, pp. 341-348, Jul. 2013.

[46] C. Vásquez, P. Díaz-Calderón, J. Enrione, and S. Matiacevich, "State diagram, sorption isotherm and color of blueberries as a function of water content," Thermochimica Acta, vol. 570, pp. 815 , outubro 2013

[47] M. H. Saeidirad, A. Rohani, and S. Zarifneshat, "Predictions of viscoelastic behavior of pomegranate using artificial neural network and Maxwell model," Computers and Electronics in Agriculture, vol. 98, no. Supplement C, pp. 1-7, Oct. 2013.

[48] M. H. Nadian, S. Rafiee, M. Aghbashlo, S. Hosseinpour, and S. S. Mohtasebi, "Continuous real-time monitoring and neural network modeling of apple slices color changes during hot air drying," Food and Bioproducts Processing, vol. 94, no. Supplement C, pp. 263-274, Apr. 2015.

[49] M. S. Rahman, M. M. Rashid, and M. A. Hussain, "Thermal conductivity prediction of foods by Neural Network and Fuzzy (ANFIS) modeling techniques," Food and Bioproducts Processing, vol. 90, no. 2, pp. 333-340, Apr. 2012.

[50] J. Wang, H. Yue, and Z. Zhou, "An improved traceability system for food quality assurance and evaluation based on fuzzy classification and neural network," Food Control, vol. 79, no. Supplement C, pp. 363-370, Sep. 2017.

[51] R. A. Rocha, I. M. Paiva, V. Anjos, M. A. M. Furtado, and M. J. V. Bell, "Quantification of whey in fluid milk using confocal Raman microscopy and artificial neural network," Journal of Dairy Science, vol. 98, no. 6, pp. 3559-3567, Jun. 2015.

[52] G. Binetti, et al., "Cultivar classification of Apulian olive oils: Use of artificial neural networks for comparing NMR, NIR and merceological data," Food Chemistry, vol. 219, no. Supplement C, pp. 131-138, Mar. 2017.

[53] A. O. Oladunjoye, S. A. Oyewole, S. Singh, and O. A. Ijabadeniyi, "Prediction of Listeria monocytogenes ATCC 7644 growth on fresh-cut produce treated with bacteriophage and sucrose monolaurate by using artificial neural network," LWT - Food Science and Technology, vol. 76, no. Part A, pp. 9-17, Mar. 2017

[54] L. Pan, Q. Zhang, W. Zhang, Y. Sun, P. Hu, and K. Tu, "Detection of cold injury in peaches by hyperspectral reflectance imaging and artificial neural network," Food Chemistry, vol. 192, no. Supplement C, pp. 134-141, Feb. 2016.

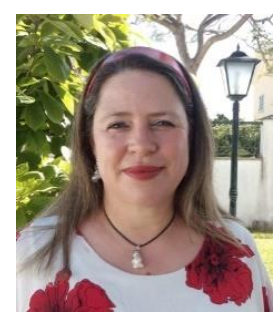

Raquel P. F. Guiné has a degree in Chemica Engineering (1991), a MsC in Engineering Science (1997) and a $\mathrm{PhD}$ in Chemical Engineering (2005), all at the Faculty of Science and Technology of the University of Coimbra (Portugal). She has a Teaching Habilitation in Food Science (2015) from the University of Algarve (Portugal). She has a Certificate of Proficiency in English (CPE, 1986) by the University of Cambridge (United Kingdom). Her major fields of study include food engineering, food processing and food science.

She has been a University Teacher since 1994, being presently a Coordinating Professor with Habilitation at the Food Industry Department in Polytechnic Institute of Viseu - IPV (Portugal). Has been President of the Scientific Board; President of the Assembly of Representatives; Director of Licence Course, Director of MsC Course, and presently is Head of Department all at ESAV, IPV (Portugal). Is author of 16 books, 40 chapters, 171 research papers and 201 conference proceedings. Has authored 136 oral communications and 96 posters presented at scientific conferences. Selected published books: Food Drying and Dehydration: Technology and Effect on Food Properties. (Germany: LAP Pub, 2015); Engineering Aspects of Cereal and Cereal-Based Products (USA: CRC Press, 2013); Vitamin C. Dietary Sources, Technology, Daily Requirements and Symptoms of Deficiency (USA: Nova Science Publishers, 2013); Handbook of Fruit and Vegetable Flavors (USA: John Wiley \& Sons, 2010). Her research interests include areas such as food engineering, food processing, food properties, food chemistry and nutrition.

Prof. Guiné is a member of the Portuguese Chemical Society (SPQ) and Asia-Pacific Chemical, Biological \& Environmental Engineering Society (CBEES). Awards: 2011 - Research Project distinguished (Project lead by her); 2011 - Certificate of Excellence of paper published in Food and Bioproducts Processing in 2010; 2013 - First Prize in the National Contest sponsored by the CAP relative to a new food developed; 2015 - Certificate of Excelence for oral comunication presented at 2nd International Conference on Food and Nutrition Technology (ICFNT 2015), Jeju Island, Republic of Korea; 2015 - Best Scientific Paper CI\&DETS Published in 2014, in the Research Group in Food, Agrarian and Veterinary Sciences; 2016 - Certificate of Best Oral Presentation for communication presented at the 2nd International Conference on Food and Agricultural Engineering (ICFAE 2016), Copenhagen, Denmark; 2016 - Third Prize in the Regional Contest Poliempreende relative to a new entrepreneurship idea; 2016 - Best Scientific Paper CI\&DETS Published in 2015, in the Research Group in Food, Agrarian and Veterinary Sciences; 2017 - Winner of the prize CEI-IIT - Research, Innovation and Territory with a project about Family Agriculture. (URL: www.raquelguine.pt) 